\title{
Technical Note: An assessment of the accuracy of the RTTOV fast radiative transfer model using IASI data
}

\author{
M. Matricardi \\ ECMWF Shinfield Park, Reading, Berkshire, RG2 9AX, UK \\ Received: 25 February 2009 - Published in Atmos. Chem. Phys. Discuss.: 14 April 2009 \\ Revised: 25 August 2009 - Accepted: 25 August 2009 - Published: 21 September 2009
}

\begin{abstract}
IASI measurements of spectral radiances made between the 1st April 2008 and the 15th April 2008 are compared with simulations performed using the RTTOV fast radiative transfer model utilizing regression coefficients based on different line-by-line models. The comparisons are performed within the framework of the European Centre for Medium-Range Weather Forecasts Integrated Forecast System using fields of temperature, water vapour and ozone obtained from short-range forecasts. Simulations are performed to assess the accuracy of the RTTOV computations and investigate relative differences between the line-by-line models and the quality of the spectroscopic databases on which the RTTOV coefficients are based.
\end{abstract}

\section{Introduction}

The exploitation of satellite radiance data for Numerical Weather Prediction (NWP) requires the use of an accurate and fast radiative transfer (RT) model to simulate radiances from an input atmospheric profile. The high spectral resolution of radiances measured by the Atmospheric Infrared Sounder (AIRS) (Aumann et al., 2003) on the Earth Observing System (EOS) Aqua platform and the Infrared Atmospheric Sounding Interferometer (IASI) (Chalon et al., 2001) on the MetOp-A platform provides temperature and constituent profiles at a higher accuracy and with more vertical resolution than the conventional filter wheel radiometers. The assimilation of AIRS and IASI long-wave temperature sounding channels at ECMWF has produced a significant positive impact on forecast quality (McNally et al., 2006; Collard and McNally, 2008) and in the near future the use of IASI data could be extended to other spectral bands. The

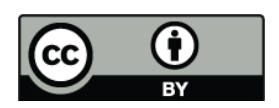

Correspondence to: M. Matricardi (marco.matricardi@ecmwf.int) variational approach to the assimilation of these datasets into the ECMWF four-dimensional variational analysis scheme, 4D-Var (Rabier et al., 1998), involves the definition of the observation-error covariance matrix that is used to specify errors associated with radiance data. The observation-error covariance matrix is the sum of the instrumental-error covariance matrix and the forward-model-error covariance matrix which is based on the estimation of errors associated with fast RT models. The low noise level of IASI and AIRS makes RT errors an important contribution to the definition of the observation-error covariance matrix and consequently they must be properly evaluated and their origin fully understood.

The fast RT model used operationally at the European Centre for Medium-Range Weather Forecasts (ECMWF) is the Radiative Transfer Model for TOVS (RTTOV) (Saunders et al., 1999). In RTTOV the transmittances of the atmospheric gases are expressed as a function of profiledependent predictors. This parameterization of the transmittances makes the model computationally efficient and thus fulfils the NWP requirement of near real-time monitoring and assimilation of satellite radiance data. Fast RT model errors are dominated by two main components: the parameterization used for the atmospheric transmittances and the errors associated with the spectroscopic parameters and the computational procedures adopted in the line-by-line (LBL) models on which fast RT models are generally based. LBL models are used to perform accurate radiance and atmospheric transmittance computations at very high spectral resolution but they are too computationally expensive to be used in an NWP operational environment. In this paper we give a brief review of the current status of the RTTOV model and discuss the main features of the LBL models that have been used to derive the RTTOV coefficients for IASI focusing on the aspects that distinguish one model from another.

Errors associated with the RTTOV transmittance parameterization for the IASI channels are discussed in detail in Matricardi (2008) whereas LBL-model errors have been

Published by Copernicus Publications on behalf of the European Geosciences Union. 
investigated in several studies (e.g. Rizzi et al., 2002; Tjemkes et al 2003) using high-spectral resolution aircraft data. In this paper we try to assess the absolute accuracy of the RTTOV model as a whole. The availability of RTTOV regression coefficients based on different LBL-models has also offered the opportunity to investigate relative differences between LBL-models and the quality of the spectroscopic databases used in the LBL-model computations. The assessment of the RTTOV accuracy has been carried out by running a number of ECMWF Integrated Forecast System (IFS) monitoring experiments where IASI spectra simulated by RTTOV have been compared to IASI spectra measured during the period $1^{\text {st }}$ April 2008-15 ${ }^{\text {th }}$ April 2008 using short range operational forecasts of temperature, water vapour and ozone fields to specify the RTTOV input state vector.

\section{The RTTOV model}

The RTTOV model was originally developed at ECMWF (Eyre and Woolf, 1988) to retrieve temperature and humidity profiles from the Television InfraRed Observation Satellite (TIROS-N) Operational Vertical Sounder (TOVS) (Smith et al., 1979). Subsequently the code has gone through several developments (e.g. Matricardi et al., 2004), more recently within the EUMETSAT NWP Satellite Application Facility (SAF), of which RTTOV-9 is the latest version (Saunders et al., 2008). RTTOV covers the spectral range $500 \mathrm{~cm}^{-1}$ to $3300 \mathrm{~cm}^{-1}$ in the infrared and the frequency range 10 $200 \mathrm{GHz}$ in the microwave and supports a large number of platforms and sensors with updates as new sensors are launched. An important feature of the RTTOV model that is essential for use in a NWP environment is that it not only performs the fast computation of the forward (or direct) radiances but also the fast computation of the gradient of the radiances with respect to the state vector variables for the input state vector values (i.e. temperature, variable gas concentrations, cloud and surface properties).

The model uses the polychromatic form of the radiative transfer equation (i.e. the use of channel averaged transmittances in the radiative transfer equation is based on the assumption that this is equivalent to the convolution of the monochromatic radiances) (see Matricardi et al., 2004, for details). The polychromatic approximation is adequate when channels are narrow enough that the convolution of the Planck function can be replaced with its value at the central wave number of the channel. For IASI and AIRS channels the polychromatic approximation results in errors typically below $0.05 \mathrm{~K}$ whereas for broad channels the accuracy is generally poor and can result in biases of $\sim 1-2 \mathrm{~K}$ (Brunel and Turner, 2003). The RTTOV fast transmittance scheme uses regression coefficients derived from accurate LBL computations to express the optical depths as a linear combination of profile dependent predictors that are functions of temperature, absorber amount, pressure and viewing angle (Ma- tricardi and Saunders, 1999). The regression coefficients are computed using a training set of diverse atmospheric profiles chosen to represent the range of variations in temperature and absorber amount found in the atmosphere. Regression coefficients for RTTOV are available based on the 43 profile training set described in Matricardi and Saunders (1999), the 52 profile training set described in Chevallier (2000) and, more recently, on the 83 profile training set described in Matricardi (2008) (hence after we will refer to these training sets as ECMWF_43_P, ECMWF_52_P and ECMWF_83_P respectively). The latter dataset includes variable profiles of carbon dioxide $\left(\mathrm{CO}_{2}\right)$, nitrous oxide $\left(\mathrm{N}_{2} \mathrm{O}\right)$, methane $\left(\mathrm{CH}_{4}\right)$ and carbon monoxide $(\mathrm{CO})$ in addition to water vapour $\left(\mathrm{H}_{2} \mathrm{O}\right)$ and ozone $\left(\mathrm{O}_{3}\right)$. The LBL computations for the minor gases that are not allowed to vary in RTTOV are carried out assuming a climatological mean profile (see next section for details).

The RTTOV-9 fast transmittance algorithm supports a range of predictor sets, namely RTTOV-7 predictors, RTTOV-8 predictors and RTTOV-9 predictors. The selection of the predictors is made according to the coefficients file supplied to the program. The RTTOV-8 predictors (Matricardi et al., 2004) allow to vary the amounts of $\mathrm{H}_{2} \mathrm{O}, \mathrm{O}_{3}$ and optionally $\mathrm{CO}_{2}$ whereas the RTTOV-9 predictors (Matricardi, 2003) allow to vary the amounts of $\mathrm{H}_{2} \mathrm{O}, \mathrm{O}_{3}, \mathrm{CO}_{2}$, $\mathrm{N}_{2} \mathrm{O}, \mathrm{CH}_{4}$ and CO. Coefficients based on RTTOV-9 predictors can only be used for AIRS and IASI and input profiles for $\mathrm{CO}_{2}, \mathrm{~N}_{2} \mathrm{O}, \mathrm{CH}_{4}$ and $\mathrm{CO}$ are mandatory. In addition, RTTOV-9 predictors can be used to compute optical depths for the long atmospheric paths involved in the computation of top of the atmosphere (TOA) radiances if solar radiation is required to be included in the short-wave infrared channels.

Regression coefficients are computed separately for all gases with fixed amounts and for each species that is allowed to vary. Since the convolution of the transmittance of all the gases differs from the product of the transmittance of the single gases convolved individually, effective transmittances are derived that allow Beer's law to be obeyed to a very good approximation (Matricardi and Saunders, 1999). The accuracy of the fast model transmittance parameterization can be assessed by comparing the transmittances and radiances computed by the fast model with the corresponding values from LBL models in different ways. Firstly, the fast model transmittance profiles and TOA radiances computed for the regression training data set can be compared with LBL model equivalents to determine the accuracy of the fast model itself. Secondly, a set of profiles independent of the regression coefficients can be used to allow uncertainties from different type of profiles to be included. The accuracy of the RTTOV9 predictors is discussed in detail in Matricardi (2008). Results for an independent profile set show that the root mean square (rms) of the difference between fast model and LBL radiances is below $0.15 \mathrm{~K}$ for the vast majority of the channels. Larger errors are observed in spectral regions that see the presence of medium strength water vapour lines, in the ozone $v 3$-band $\left(1000-1080 \mathrm{~cm}^{-1}\right)$ and in regions where $\mathrm{H}_{2} \mathrm{O}$ 
lines interfere with absorption lines of other gas species. Results for RTTOV-8 predictors are similar (Matricardi et al., 2004). If we use this error figure as representative of errors associated with the RTTOV fast transmittance parameterization then we can reasonably assume that the RTTOV accuracy is largely determined by the accuracy of the LBL algorithm. For instance the inaccurate knowledge of molecular line strengths alone can result in TOA radiance errors as large as 0.3-0.4 K (Rizzi et al., 2002).

The computation of TOA radiances in RTTOV-9 is performed using a parameterization of the Planck function based on the linear-in- $\tau$ assumption that the source function throughout an atmospheric layer is linear with the optical depth, $\tau$, of the layer. An altitude dependent correction to the local path is also applied that takes into account the curvature of the Earth and its surrounding atmosphere. Finally, to compute the infrared emissivity over water a fast surface emissivity routine, ISEM, (Sherlock, 1999) is used.

\section{The line-by-line models}

As discussed in the previous section, the RTTOV fast transmittance algorithm uses regression coefficients obtained from LBL transmittance calculations. As noted in Rizzi et al. (2002), LBL model errors tend to be dominated by insufficient knowledge of basic spectroscopy rather than by the computational procedures used in the codes. Spectroscopic errors are of paramount importance for highresolution sounders like AIRS and IASI that allow the use of channels placed between spectral lines. These channels have weighting functions that are sharper than the weighting functions that characterize the channels placed on top of the spectral lines and consequently particular attention must be paid to the spectral line shape of species like $\mathrm{H}_{2} \mathrm{O}$ and $\mathrm{CO}_{2}$ for which optical depths in the atmosphere can reach very large values. The effect of line mixing, i.e. the change in line shape due to the redistribution of radiation in overlapping spectral lines (Strow and Reuter, 1988), in the $\mathrm{CO}_{2}$ Q-branches is now routinely incorporated in LBL algorithms and in the recent past progress has been made in the development of improved $\mathrm{CO}_{2}$ line shapes by taking into account the effect of line mixing in $\mathrm{CO}_{2} \mathrm{P} / \mathrm{R}$-branches (e.g. Niro et al., 2005). Progress in the development of improved $\mathrm{H}_{2} \mathrm{O}$ line shapes is still hindered by the difficulty of achieving good measurements of $\mathrm{H}_{2} \mathrm{O}$ amounts in the atmosphere and in the laboratory and the nature of water vapour continuum absorption and its effect on atmospheric radiance is an outstanding and unresolved issue (e.g. Ma et al., 2008). In the vast majority of LBL models, water vapour continuum is parameterized using the semi-empirical CKD model by Clough et al. (1989) or, alternatively, the semi-empirical MT_CKD model (Clough et al., 2005). The main difference between the CKD and the MT_CKD model resides in the fact that the MT_CKD model is based on the assumption that the con- tinuum absorption in water vapour bands is dominated by the collision-induced absorption resulting from the generation of a short-lived complex of water vapour and colliding molecules. Finally, the accuracy of the line parameters used in the LBL calculations can introduce significant errors in the simulated radiances (Tjemkes et al., 2003).

RTTOV regression coefficients for IASI are available based on various LBL models. Regression coefficients based on version 4 of the GENLN2 LBL model (GENLN2_v4) and version 11.1 of the LBLRTM LBL model (LBLRTM_v11.1) have been generated at ECMWF using RTTOV-9 predictors whereas coefficients based on version 1.11 of the kCARTA LBL model (kCARTA_v1.11) have been generated at Meteo France using RTTOV_8 predictors. A description of the LBL models is given in the following sections.

\subsection{GENLN2_v4}

GENLN2_v4 (Edwards, 1992) is a line-by-line atmospheric transmittance and radiance model. Line strengths and halfwidths are adjusted to the path pressure and temperature and Doppler broadening of the spectral lines is taken into account. To describe the effects of pressure and Doppler line broadening, GENLN2_v4 adopts the Voigt line shape. The GENLN2_v4 $\mathrm{CO}_{2}$ line shape includes the effect of line mixing and takes into account the sub-Lorentzian behaviour in the far-wing of the line. If data is available, $\mathrm{CO}_{2} \mathrm{Q}$ branch line mixing in the $v 2$-region $\left(600-800 \mathrm{~cm}^{-1}\right)$ and $v 3$ region $\left(2200-2500 \mathrm{~cm}^{-1}\right)$ can be included out to an arbitrary $10 \mathrm{~cm}^{-1}$ from line centre. For greater distances from the centre the line shape is approximated by the empirical model by Cousin et al. (1985). This model explains the sub-Lorentzian nature of the $\mathrm{CO}_{2}$ far wing line shape in terms of duration of collision effects and uses a temperature dependent $\chi$-factor to adjust the standard line shape function based on the impact theory. If no line-mixing data is available then the subLorentzian line shape is used everywhere.

The standard release of GENLN2_v4 includes version 2.1 of the CKD water vapour continuum model (hence after referred to as CKD_v2.1). However, we carried out our computations using version 2.4 of the CKD model (hence after referred to as CKD_v2.4) that became available at the time the regression coefficients were about to be generated. The pressure-broadened band of $\mathrm{N}_{2}$ at $2350 \mathrm{~cm}^{-1}$ (Menoux at al., 1993) and that of $\mathrm{O}_{2}$ at $1550 \mathrm{~cm}^{-1}$ (Timofeyev and Tonkov, 1978; Rinsland et al., 1989) is included as broadband continuum contribution to the absorption and heavy molecules can be modeled using high-resolution cross-sectional data. In our computations, $\mathrm{CO}_{2} \mathrm{Q}$-branch line mixing has been fully accounted for using first order line-mixing coefficients from Strow et al. (1994). 
Table 1. The LBL datasets used for the training of RTTOV.

\begin{tabular}{llll}
\hline LBL model & Continuum & $\mathrm{CO}_{2}$ line mixing & Molecular Database \\
\hline $\begin{array}{l}\text { kCARTA } \\
\begin{array}{l}\text { Number of levels: 101 } \\
\text { Profile training set: ECMWF_52_P }\end{array}\end{array}$ & MT_CKD_v1.0_UMBC & $\begin{array}{l}\text { P/Q/R branch } \\
(v 2 \text { and } v \text { 3 band })\end{array}$ & HITRAN_2000 \\
\hline $\begin{array}{l}\text { GENLN2 } \\
\text { Number of levels: 101 }\end{array}$ & CKD_v2.4 & Q branch & HITRAN_2000 \\
Profile training set: ECMWF_43_P & & $(v 2$ and $v 3$ band $)$ & \\
\hline $\begin{array}{l}\text { LBLRTM } \\
\text { Number of levels: 101 } \\
\text { Profile training set: ECMWF_83_P }\end{array}$ & MT_CKD_v2.0 & P/Q/R branch & HITRAN_2000 \\
\end{tabular}

\section{2 kCARTA_v1.11}

The kCARTA_v1.11 model (De Souza-Machado et al., 2002) is a pseudo LBL algorithm where transmittances are computed from compressed look-up tables of atmospheric transmittances (Strow et al., 1998). The look-up tables are computed using a LBL model developed at the University of Maryland, Baltimore County (UMBC-LBL) (Strow et al., 2003) and their use in KCARTA results in very fast computation times. The water vapour continuum model (hence after referred to as MT_CKD_v1.0_UMBC) is based on version 1.0 of the MT_CKD model (hence after referred to as MT_CKD_v1.0). It uses revised values of the spectral density function coefficients based on measurements of AIRS spectra utilizing in-situ data available from the ARM sites (De Souza-Machado, personal communication, 2008). Line mixing coefficients for $\mathrm{CO}_{2}$ are available for $12 \mathrm{P} / \mathrm{R}$-branch bands and 12 Q-branch bands in the short wave and in the long wave. The kCARTA model for the $\mathrm{CO}_{2}$ line shape is based on the work by Tobin (1996) and De Souza-Machado et al. (1999). For the P/R-branch it involves an approximation for the combination of line mixing and duration-ofcollision effects. Regarding the UMBC-LBL model it should be stressed that it relies on a full treatment of the $\mathrm{CO}_{2} \mathrm{Q}$ and P/R-branch line mixing and does not use the perturbation theory. Finally, the collision-induced bands of oxygen at $1600 \mathrm{~cm}^{-1}$ and nitrogen at $2350 \mathrm{~cm}^{-1}$ are incorporated using the model by Thibault et al. (1997) and Lafferty et al. (1996) respectively.

\subsection{LBLRTM_v11.1}

The LBLRTM line-by-line model (Clough et al., 2005) has been developed at the Atmospheric and Environmental Research Inc. (AER). To describe the effects of pressure and Doppler line broadening the Voigt line shape is used at all atmospheric levels with an algorithm based on a linear combination of approximating functions. LBLRTM incorporates version 2.0 of the water vapor continuum model MT_CKD (hence after referred to as MT_CKD_v2.0) and the collision-induced bands of oxygen at $1600 \mathrm{~cm}^{-1}$ and nitrogen at $2350 \mathrm{~cm}^{-1}$ are included as broad-band continuum contributions to the absorption using the models by Thibault et al. (1997) and Lafferty et al. (1996) respectively. In LBLRTM the $\mathrm{CO}_{2}$ line shape includes the effects of line mixing for the P-R-branch and Q-branch in the $v 2$-region and $v 3$-region using first order line coupling parameters generated using the code by Niro et al., 2005. Since the model by Niro et al. (2005) combines the effects of line mixing and duration of collision effects, the $\chi$ factor is set equal to 1 . In addition, the $\mathrm{CO}_{2}$ continuum is computed using the Niro et al. (2005) coupling coefficients with a scaling factor of 0.75 applied to the v3-region to agree with AIRS spectra in this spectral region (for details on the LBLRTM $\mathrm{CO}_{2}$ continuum see Shepard et al., 2009). LBLRTM uses temperature dependent cross section data to model the absorption of heavy molecules. The pressure dependence of the cross sections is treated by performing a convolution of the cross section spectrum with an appropriate Lorentz function.

\section{The database of line-by-line transmittances}

The computation of the LBL transmittances used to train the RTTOV fast RT model is performed on a grid of vertical levels of fixed pressure for a regression dataset of diverse atmospheric profiles and require the use of appropriate parameters from a molecular database. These details are summarized in Table 1. Note how for KCARTA and GENLN2 the same molecular database has been used although it should be noted that for GENLN2 the use of the Strow et al.(1994) line mixing coefficients requires the use of $\mathrm{CO}_{2}$ molecular line parameters from the HITRAN_1992 compilation. For the LBLRTM computations we have created a molecular database that blends line parameters obtained from various sources. This is based on the results shown in Matricardi (2007) which suggest that in a number of spectral regions the use of line parameters from different sources can result in a better agreement of simulations with observations. This blended database is based on the AER line 
Self broadening

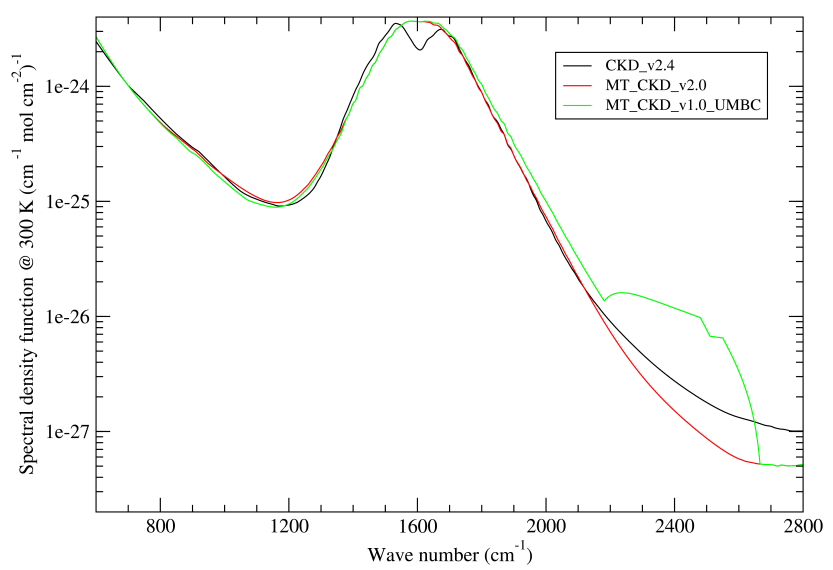

Fig. 1. Spectral density function for the water vapour self broadening coefficients at $300 \mathrm{~K}$ and $1013 \mathrm{hPa}$.

file supplied with the LBLRTM_v11.1 package. The AER line file is largely drawn from HITRAN_2004 (Rothman et al., 2005) and includes updates up to 1/1/2007. However, for the ozone region between $1000 \mathrm{~cm}^{-1}$ and $1080 \mathrm{~cm}^{-1}$ we use ozone line parameters from HITRAN_2000 (Rothman et al., 2003) whereas in the spectral region between 1700 and $2400 \mathrm{~cm}^{-1}$ we use water vapour line parameters from GEISA_2003 (Jaquinet-Husson et al., 2005). Although Matricardi (2007) suggests that the use of $\mathrm{CO}_{2}$ line parameters from GEISA_2003 could also be envisaged for the $\mathrm{CO}_{2}$ v3region between $645 \mathrm{~cm}^{-1}$ and $800 \mathrm{~cm}^{-1}$, the use of Niro et al. (2005) line mixing coefficients requires that line parameters for $\mathrm{CO}_{2}$ are obtained from the HITRAN_2000 compilation. From Table 1 it can also be seen that regression coefficients are based on different profile training sets and that all the computations have been performed on the 101 level vertical grid specified by the AIRS science team (Strow et al., 2003).

For the interpretation of the results we find it useful to include two figures where differences between the various water vapour continuum models are illustrated. In particular, in Fig. 1 we show the water vapour broadening coefficients for the self continuum while in Fig. 2 we show the broadening coefficients for the foreign continuum (self broadening due to $\mathrm{H}_{2} \mathrm{O}-\mathrm{H}_{2} \mathrm{O}$ collisions is the dominant source of continuum in the window regions whereas foreign broadening due $\mathrm{H}_{2} \mathrm{O}-\mathrm{N}_{2}$ collisions dominates in the water vapour band). These figures show that in the window region between $800 \mathrm{~cm}^{-1}$ and $1200 \mathrm{~cm}^{-1}$ the MT_CKD_v1.0_UMBC self broadening coefficients are smaller than CKD_v2.4 and MT_CKD_v2.0 coefficients. In the centre of the water vapour band around $1600 \mathrm{~cm}^{-1}$ the CKD_v2.4 foreign broadening coefficients are smaller than MT_CKD_v.1.0_UMBC and MT_CKD_v2.0 coefficients whereas for wavenumbers greater than $1600 \mathrm{~cm}^{-1}$ and
Foreign broadening

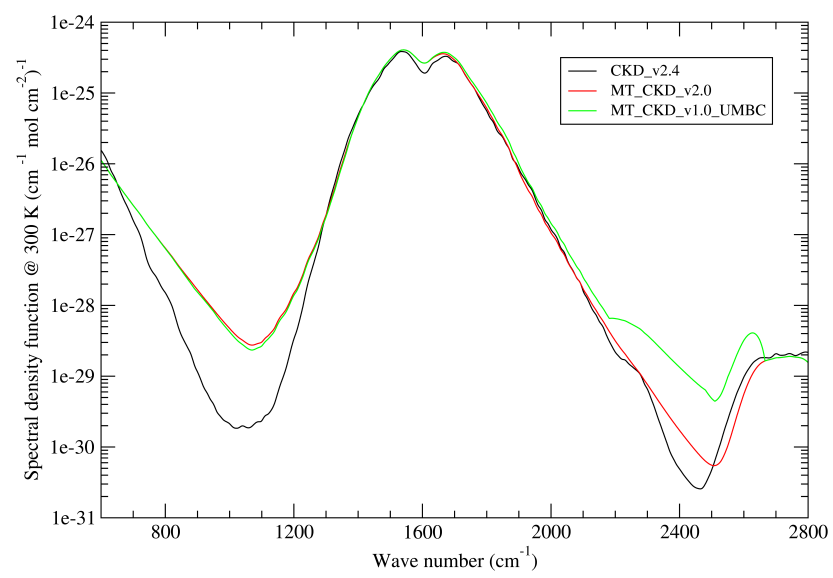

Fig. 2. Spectral density function for the water vapour foreign broadening coefficients at $300 \mathrm{~K}$ and $1013 \mathrm{hPa}$.

smaller than $2650 \mathrm{~cm}^{-1}$ the MT_CKD_v1.0_UMBC foreign broadening coefficients are larger than CKD_v2.4 and MT_CKD_v2.0 coefficients. It should be noted that in the spectral region between $2200 \mathrm{~cm}^{-1}$ and $2600 \mathrm{~cm}^{-1}$ the shape of the MT_CKD_v1.0_UMBC model differs significantly from that of the other continua. The rather unphysical shape of the MT_CKD_v1.0_UMBC model could suggest that the UMBC modifications to the MT_CKD_v2.1 model have been used to correct for an effect that is not, in fact, due to water vapour absorption.

All LBL datasets include $\mathrm{N}_{2}, \mathrm{O}_{2}, \mathrm{HNO}_{3}, \mathrm{OCS}, \mathrm{CCl}_{4}, \mathrm{CF}_{4}$, $\mathrm{CCl}_{3} \mathrm{~F}$ and $\mathrm{CCl}_{2} \mathrm{~F}_{2}$ among the gases with fixed amount. Regression coefficients based on the GENLN2 and LBLRTM models allow the variation of $\mathrm{CO}_{2}, \mathrm{~N}_{2} \mathrm{O}, \mathrm{CO}$, and $\mathrm{CH}_{4}$ amounts whereas in kCARTA the amount of these gas species is fixed. The LBLRTM dataset includes an additional number of fixed gas species, i.e. $\mathrm{NO}_{2}, \mathrm{SO}_{2}$ and $\mathrm{NO}$. In general, atmospheric constituent profiles for all gases are based on AFGL profiles scaled to reflect present-day concentrations. However, in the LBLRTM dataset we have used $\mathrm{HNO}_{3}$ and NO profiles generated using the MOZART chemical transport model (Hauglustaine et al., 1998) whereas in the kCARTA dataset the concentrations of $\mathrm{CO}_{2}, \mathrm{~N}_{2} \mathrm{O}, \mathrm{CO}$ and $\mathrm{CH}_{4}$ are based on the climatological profiles described in Matricardi (2003).

\subsection{The monitoring experiments}

As discussed in the introduction, the assessment of the RTTOV accuracy has been carried out by running a number of IFS monitoring experiments where spectra measured by IASI have been compared to spectra simulated by RTTOV. The state vector variables used in the RTTOV simulations are forecast fields of temperature, humidity, ozone and surface parameters. IASI data within a $12-\mathrm{h} 4 \mathrm{D}-$ Var window 
are grouped into $30 \mathrm{~min}$ time slots. A high resolution forecast is then run from the previous analysis and observation minus model differences are computed for IASI soundings within a given time slot. This sequence is then repeated for each 12-h 4D-Var window. In this study we consider IASI data inside 12 -h $4 \mathrm{D}$-Var windows during the period 1 April 2008-15 April 2008.

The forecast fields used in this study have been generated using version 33R1 of the ECMWF model (the so-called cycle 33R1 of the ECMWF Integrated Forecast System which was operational from June until October 2008) using a spectral representation in the horizontal truncated at 799 waves (T999). This truncation corresponds to a horizontal resolution of $\sim 25 \mathrm{~km}$. A feature of IFS cycle 33R 1 is a vertical discretization of the atmosphere into a grid of 91 pressure levels. The model uses a hybrid vertical coordinate with coordinates that follow the orography of the terrain in the lower troposphere and pressure coordinates in the stratosphere above about $60 \mathrm{hPa}$. The top level is fixed at $0.01 \mathrm{hPa}$ (about $80 \mathrm{~km}$ ) and of the 91 levels in the vertical, 52 are above $100 \mathrm{hPa}$. The statistics of the difference between global radiosonde observations and ECMWF analyses in the troposphere show values of the standard deviation typically between $0.5 \mathrm{~K}$ and $1 \mathrm{~K}$ for temperature and between 0.5 and $1.5 \mathrm{~g} / \mathrm{Kg}$ for water vapour. In the stratosphere, standard deviations for temperature can reach $1.5 \mathrm{~K}$. Ancillary data used in the RTTOV computations include sea-surface temperature (SST). SST fields in cycle 33R 1 are based on analyses received from the National Centers for Environmental Prediction (NCEP), Washington DC, on a $0.5^{\circ} \times 0.5^{\circ}$ grid. These analyses are based on ship, buoy and satellite observations. The SST root mean square error (rms) relative to buoy observations is $0.36 \mathrm{~K}$ with a mean bias of $-0.02 \mathrm{~K}$ (Kara et al., 2007). However, this figure can be significantly different in shallow waters where rapid changes due to the upwelling radiation can occur close to land.

Since the the RTTOV optical depth computations are defined by the number of levels in the coefficient file, the IFS pressure levels must be interpolated to the same levels as the coefficient files. To this end we have used the RTTOV-9 new internal interpolation scheme that allows the input profile to be defined by the user. However, it should be noted that although RTTOV computes optical depths on the levels specified in the coefficient files, the integration of the RT equation is performed on the 91 IFS levels. To ensure that the Jacobians are properly mapped back on the user levels, the optical depths must be interpolated to the IFS levels using the same interpolation scheme utilized for the atmospheric variables.

The IASI spectra used in our experiments are measured over the sea. To reduce the amount of data we have subsampled by arbitrarily selecting one out of eleven scanpositions. This also ensures that for two adjacent scan lines we always sample two different scan positions. Only channels detected as clear by the ECMWF cloud detection algorithm are processed. Since the ECMWF cloud detection
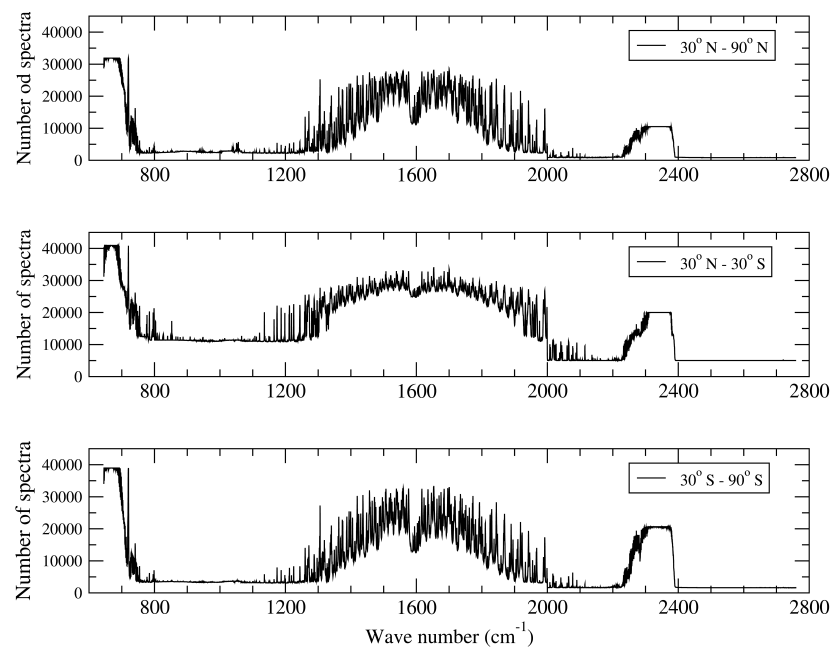

Fig. 3. The number of spectra sampled as clear for each IASI channel for three different latitude bands.

algorithm (McNally and Watts 2003) finds clear channels rather than clear locations, the size of sample varies with the sensitivity of the channel to clouds. Channels characterized by weighting functions that peak at high altitudes are less sensitive to clouds than channels with weighting functions that peak at low altitudes or at the surface. To illustrate this, in Fig. 3 we show the size of the sample for each channel in three latitude bands. It can be clearly seen that the size of the sample varies from several thousands of spectra for the channels peaking at middle and high altitudes to a few thousand for channels peaking at low altitudes or at the surface. To avoid reflected solar radiation and non-LTE effects (the latter are not modelled in RTTOV), in the spectral region between 2000 and $2760 \mathrm{~cm}^{-1}$ we have sampled only night-time spectra. This is reflected in Fig. 3 where the size of the sample in this spectral region is significantly smaller than the size of the sample in other spectral regions. Note that to exclude day-time spectra we have used the criterium that the local solar zenith angle is greater than $100^{\circ}$. This means that a given location can be considered not to be in daylight up to an altitude of $\sim 100 \mathrm{~km}$ (i.e. the altitude above which we consider the atmosphere to be transparent in our calculations).

In this study, we have carried out three baseline experiments using RTTOV coefficients based on the GENLN2, LBLRTM and kCARTA LBL model. In our RTTOV computations, the state vector includes profiles of temperature, water vapour and ozone, surface parameters (e.g. skin temperature and surface pressure) and a wave number dependent value of the sea surface emissivity that includes the dependence on the viewing geometry. In addition to the profiles of temperature, water vapour and ozone, the experiments that use RTTOV coefficients based on GENLN2 and LBLRTM also require input profiles of $\mathrm{CO}_{2}, \mathrm{CO}, \mathrm{N}_{2} \mathrm{O}$ and $\mathrm{CH}_{4}$. These trace gases are not prognostic variables in the 

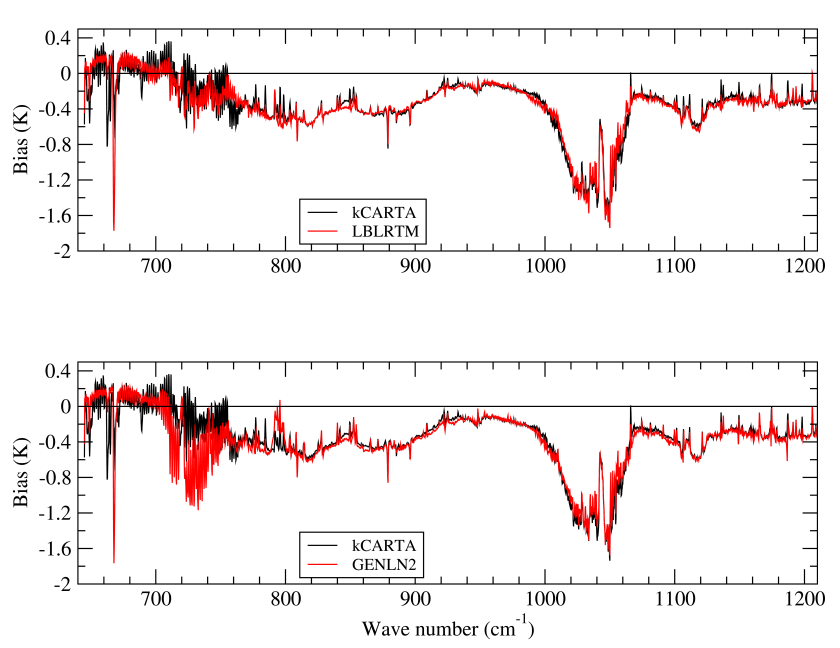

Fig. 4. The mean value of the difference between observed and computed brightness temperatures in the Northern Hemisphere for IASI band 1 .

ECMWF model and, consequently, fixed values must be used in the RTTOV computations. To this end, we have chosen the fixed values used in the RTTOV coefficients based on the kCARTA model. The rationale behind this choice is that at present, kCARTA coefficients are used operationally at ECMWF for the assimilation of AIRS and IASI radiances and we want to use the kCARTA spectra as benchmark in our comparisons.

\section{Discussion of the results}

\subsection{IASI band $1\left(645\right.$ to $\left.1200 \mathrm{~cm}^{-1}\right)$}

Results in IASI band 1 are plotted in Figs. 4, 5 and 6 where we show the mean value of the difference (bias) between observed and simulated radiances in units of equivalent black body brightness temperature for the Northern Hemisphere $\left(30^{\circ} \mathrm{N}-90^{\circ} \mathrm{N}\right)$, tropics $\left(30^{\circ} \mathrm{N}-30^{\circ} \mathrm{S}\right)$ and Southern Hemisphere $\left(30^{\circ} \mathrm{S}-90^{\circ} \mathrm{S}\right)$ respectively. In the top panel the LBLRTM spectral residuals (solid red line) are superimposed on the kCARTA spectral residuals (solid black line) whereas in the bottom panel the GENLN2 spectral residuals (solid red line) are superimposed on the kCARTA spectral residuals. Results show that for all experiments biases are generally within $\pm 1 \mathrm{~K}$ in all geographical regions. The only exception is the ozone band $\left(1000-1080 \mathrm{~cm}^{-1}\right)$ where biases can reach up to $-2 \mathrm{~K}$.

\subsubsection{Results in the temperature sounding band}

Of particular interest are the results obtained in the temperature sounding $\mathrm{CO}_{2}$ v2-region where the GENLN2 spectral residuals show significantly larger biases between $700 \mathrm{~cm}^{-1}$ and $750 \mathrm{~cm}^{-1}$. To interpret this result we should bear in mind
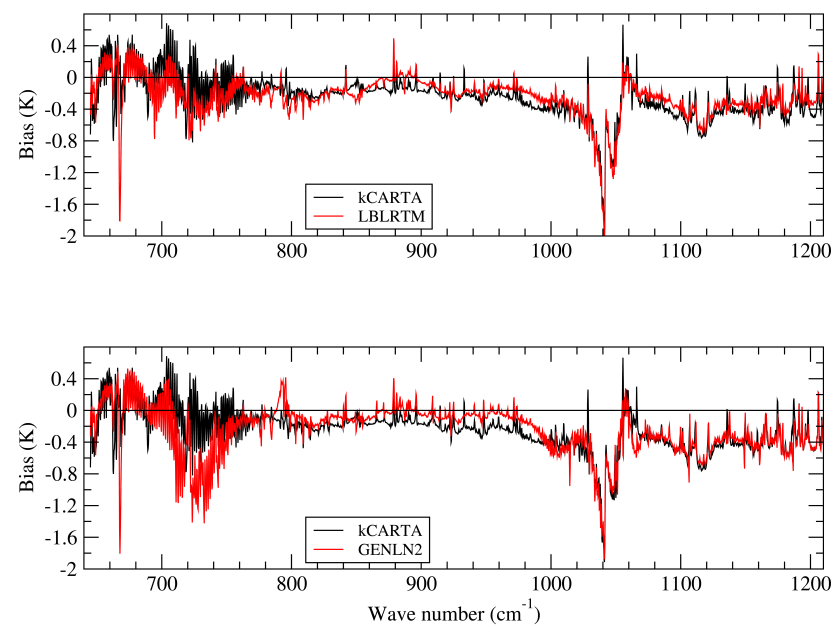

Fig. 5. The mean value of the difference between observed and computed brightness temperatures in the tropical region for IASI band 1 .
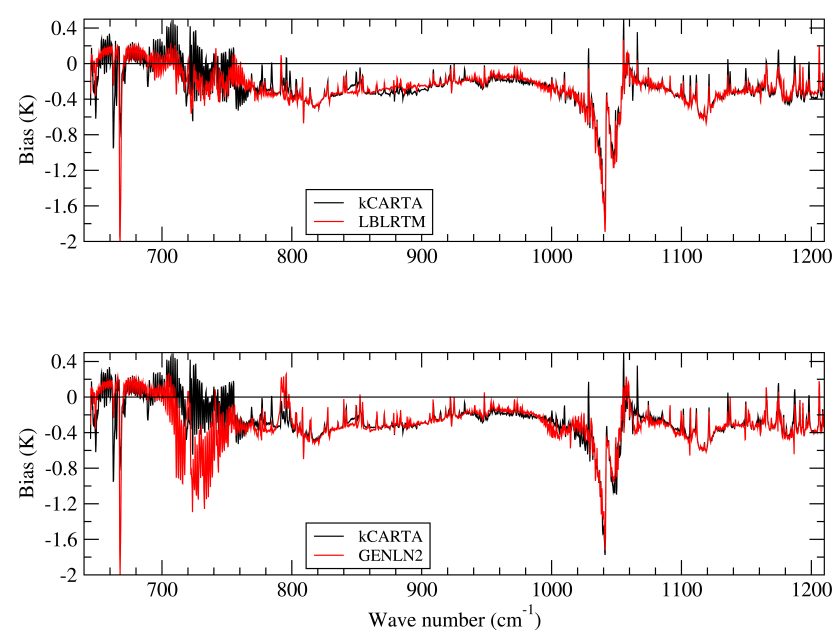

Fig. 6. The mean value of the difference between observed and computed brightness temperatures in the Southern Hemisphere for IASI band 1 .

that, as discussed in Sect, 3, GENLN2 uses the Cousin et al. (1985) empirical model to describe the far-wing shape of the $\mathrm{CO}_{2}$ line shape. The $\chi$-factor used in the $v 2$-region is based on spectra measured in the v3-region. However, the symmetry of the bands in the $v 3$-region is different from the symmetry of the bands in the $v 2$-region and consequently the component of the $\chi$ factor due to line mixing is in error and the effect of line-mixing will be over-estimated in GENLN2. As shown in Figs. 4, 5 and 6, errors in the GENLN2 $\mathrm{CO}_{2}$ line shape can significantly degrade the accuracy of the spectra.

As discussed above, the performance of GENLN2 between 700 to $750 \mathrm{~cm}^{-1}$ can be explained in terms of the different treatment of the far-wing $\mathrm{CO}_{2}$ line shape. In the same spectral region, the spectral residuals of kCARTA and 
LBLRTM show similar features with differences typically within $0.2 \mathrm{~K}$ (maximum values can reach $0.4 \mathrm{~K}$ ). However, the kCARTA spectral residuals are more irregular than the LBLRTM spectral residuals. For all LBL models, most of the residuals in this spectral region can be attributed to $\mathrm{CO}_{2}$ spectroscopy. Consequently, since KCARTA and LBLRTM use the same $\mathrm{CO}_{2}$ line parameters, the behaviour of KCARTA might reflect differences in the $\mathrm{CO}_{2}$ line shape. It should be noted that a few residuals are from weak water vapour lines originating from the edge of the water vapour pure rotational band. These residuals can be attributed to errors in the water vapour line strengths and widths due either to uncertainties in the humidity profile or to spectroscopic errors (note that kCARTA and LBLRTM use different water vapour line parameters).

The spectral residuals between 700 to $750 \mathrm{~cm}^{-1}$ can be used to gain some insight into the accuracy of the temperature profiles used in the simulations. The envelope of the spectral residuals shown in Figs. 4, 5 and 6, suggests that the lapse rate of the input temperature profile in the troposphere is not correct. In fact, spectral residuals tend to increase with wavenumbers (i.e. moving from high-peaking channels to near-surface-peaking channels). For instance, the kCARTA and LBLRTM spectral residuals are very close to zero near $700 \mathrm{~cm}^{-1}$ but they do increase to $\sim 0.5 \mathrm{~K}$ for the channels peaking near the surface. It should be stressed that any errors in the temperature field have implications for the residuals in other sounding regions since, for instance, they can propagate into $\mathrm{H}_{2} \mathrm{O}$ and $\mathrm{O}_{3}$ residual errors.

The spectral region between 645 and $700 \mathrm{~cm}^{-1}$ is characterized by the very close similarities between the LBLRTM and GENLN2 spectral residuals. A noticeable feature in common to LBLRTM and GENLN2 is the presence of large biases (typically $-1.8 \mathrm{~K}$ ) for the channels in the $\mathrm{CO}_{2}$ Q-branch at $667 \mathrm{~cm}^{-1}$. These biases are not seen in the kCARTA residuals although kCARTA residuals do exhibit larger biases around $664-665 \mathrm{~cm}^{-1}$. Since these are the only spectral regions between 645 and $700 \mathrm{~cm}^{-1}$ for which line mixing is expected to play a role, differences between LBLRTM/GENLN2 and kCARTA are probably due to $\mathrm{CO}_{2}$ line mixing. It should ne noted, however, that channels in the $\mathrm{CO}_{2}$ Q-branch at $667 \mathrm{~cm}^{-1}$ are sensitive to emission at very high altitudes; consequently, spectral residuals could be affected by systematic errors present in the ECMWF temperature profiles in the upper stratosphere and mesosphere. Elsewhere, differences between the spectral residuals probably reflect differences in the $\mathrm{CO}_{2}$ line shape due to effects other than line mixing. It should be noted that in general, differences between the spectral residuals cannot be due to the molecular parameters since, for instance, LBLRTM and kCARTA use the same HITRAN_2000 compilation.

\subsubsection{Results in the ozone sounding band}

Spectral residuals in the ozone band $\left(1000 \mathrm{~cm}^{-1}\right.$ to $1080 \mathrm{~cm}^{-1}$ ) are remarkably close for all LBL models (note that they all use the same ozone line parameters). However, the magnitude of the biases can reach large values (up to $-2 \mathrm{~K}$ ) especially in the Northern Hemisphere. Results published in the literature (for instance see Shepard et al., 2009) do not support the hypothesis that these large biases are the result of errors in the ozone spectroscopic parameters. Consequently, the residuals are probably dominated by errors in the input ozone profile due to a poor performance of the ozone assimilation system.

\subsubsection{Results in the window regions}

The absorption in the window regions between 800 and $1200 \mathrm{~cm}^{-1}$ is primarily due to water vapour and consists mainly of the absorption due to water vapour self- continuum although in the high-wavenumber boundary of the window (i.e. between 1080 and $1200 \mathrm{~cm}^{-1}$ ) the contribution of weak water vapour lines originating in the $v 2$-band has also to be taken into account. With the exception of a few channels, the specification of the continuum model and the choice of the molecular parameters do not appear to have a significant impact on the spectra obtained in the Northern and Southern Hemispheres. In fact, within each of these geographical regions, spectral residuals are very similar with biases varying between -0.1 and $-0.6 \mathrm{~K}$ in the Northern Hemisphere and between -0.1 and $-0.4 \mathrm{~K}$ in the Southern Hemisphere.

It is difficult to interpret the differences observed between the residuals obtained in the Northern and Southern Hemispheres between 800 and $1000 \mathrm{~cm}^{-1}$. The absorption due to the water vapour self continuum is proportional to the square of the water vapour amount and for a fixed amount of water vapour it decreases with temperature. In general, the colder air masses typically encountered at mid-high latitudes are associated with less water vapour and the competing effect of temperature and water amount is stronger than in the much more humid conditions encountered in the tropical regions. Errors in the temperature profiles and, above all, errors in the water vapour profiles in the lower troposphere and near the surface can then affect the simulated spectra in various measures and result in the different biases observed at different latitudes.

Biases can also be affected by errors in the SST analysis. In addition, SST errors indirectly affect the values of the sea surface emissivities computed by ISEM since ISEM does not take into account the temperature dependence of the water vapour optical parameters. However, since the SST is used as the skin temperature in the RT computations, the larger biases in the Northern Hemisphere cannot be explained in terms of SST alone since this feature should also be present in the high-wavenumber boundary of the window region. More insight can be gained by looking at isolated spectral 

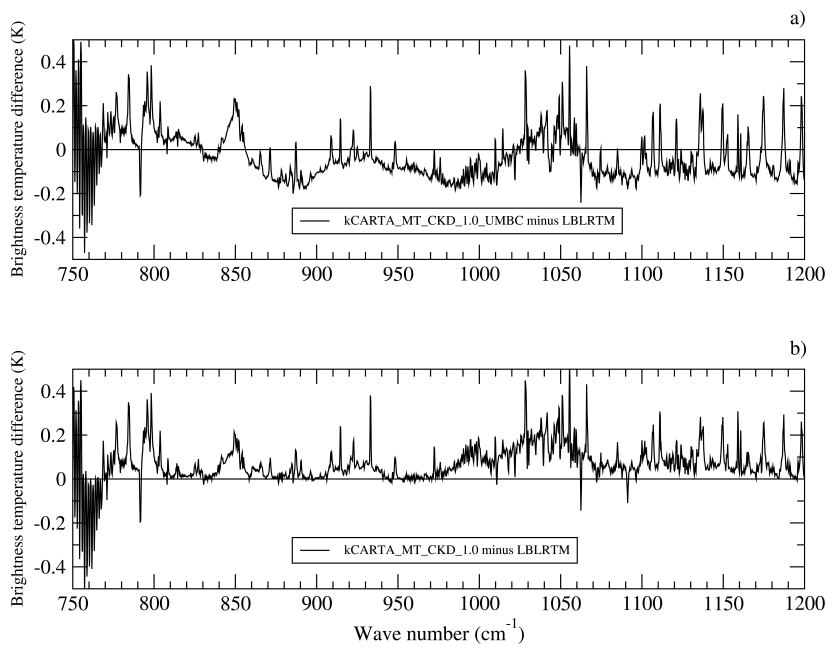

Fig. 7. The difference in IASI band 1 between (a) kCARTA_MT_CKD_1.0_UMBC and LBLRTM mean spectrum in the tropical region; (b) kCARTA_MT_CKD_1.0 and LBLRTM mean spectrum in the tropical region.

regions that are not significantly affected by water vapour continuum (e.g. $930 \mathrm{~cm}^{-1}$ and $2475 \mathrm{~cm}^{-1}$ ) where we can observe residual differences of the order of $-0.2 \mathrm{~K}$. This result would suggest that the SST values are in error by $-0.2 \mathrm{~K}$ on average. However, the $-0.2 \mathrm{~K}$ figure contrasts with the $-0.02 \mathrm{~K}$ reported by Kara et al. (2007). It is also possible that channels identified by the cloud detection scheme as clear are in fact affected by clouds. The negative sign of the biases (i.e. the RT model overestimates the radiances) is consistent with this hypothesis. However, results obtained using aircraft data in controlled clear-sky conditions (e.g. Rizzi et al., 2002) show biases whose magnitude is similar to that obtained in our study. Consequently, the effect due to errors in the cloud detections scheme must be very small.

Results for the tropical region (Fig. 5) show that in contrast to the cases discussed above, differences now exist between the spectral residuals in the window regions. This is a direct consequence of the fact that the high tropical water vapour column concentrations make the water vapour continuum absorption a much more important factor. We have studied this aspect more in depth by running a further experiment where the kCARTA spectra have been computed using the same water vapour continuum model used in LBLRTM. The results are shown Fig. 7 where we have plotted the difference between the kCARTA mean spectrum computed using the standard kCARTA continuum (hence after referred to as kCARTA_MT_CKD_1.0_UMBC spectrum) and the LBLRTM mean spectrum (top panel) and the difference between the kCARTA mean spectrum obtained using the LBLRTM continuum (hence after referred to as kCARTA_MT_CKD_1.0 spectrum) and the LBLRTM mean spectrum (bottom panel).
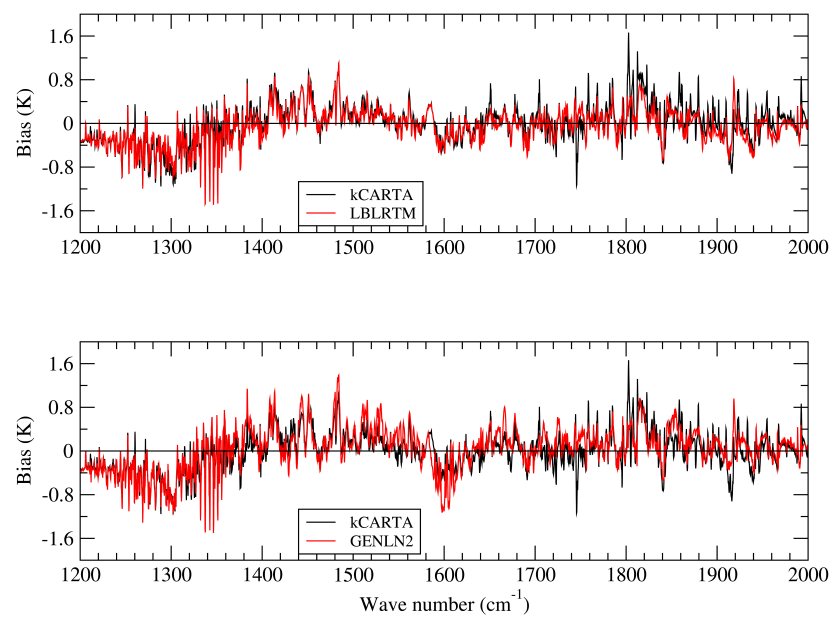

Fig. 8. The mean value of the difference between observed and computed brightness temperatures in the Northern Hemisphere for IASI band 2.

Figure 7 shows that the use of the same continuum model greatly reduce the differences between the spectra. This is all the more evident between 800 and $980 \mathrm{~cm}^{-1}$. The differences seen in correspondence of the $\mathrm{CFCl}_{3}$ band at $846 \mathrm{~cm}^{-1}$ and the $\mathrm{CF}_{2} \mathrm{Cl}_{2}$ band at $923 \mathrm{~cm}^{-1}$ are attributable to the different amounts used for these molecules in kCARTA and LBLRTM whereas differences around $880 \mathrm{~cm}^{-1}$ should be attributed to the spectroscopy. In the window region between 1080 and $1200 \mathrm{~cm}^{-1}$ the change in the continuum reduces the peak-to-peak differences and shifts the biases towards positive values. This would suggest that in this spectral region differences between the spectra are attributable primarily to differences between the molecular databases. Results shown in the bottom panel of Fig. 5 corroborate this hypothesis in that GENLN2 and kCARTA biases are in very good agreement (they use the same HITRAN_2000 molecular database).

Finally, we want to comment on the feature (a kink) in the GENLN2 spectrum around $1000 \mathrm{~cm}^{-1}$ observed in the tropics and in the Southern Hemisphere. This feature is not present in the KCARTA and LBLRTM experiments and its origin is difficult to interpret. In this spectral region, the only obvious difference between GENLN2 and the other LBL models is the much smaller value of the foreign broadening spectral density function but it is difficult to argue in favour of a possible impact of the foreign continuum since foreign broadening should not be important at these wavenumbers.

\subsection{IASI band $2\left(1200\right.$ to $\left.2000 \mathrm{~cm}^{-1}\right)$}

Spectral residuals in IASI band 2 are plotted in Figs. 8, 9 and 10 for the Northern Hemisphere, tropics and Southern Hemisphere respectively. The values of the biases vary between $-2 \mathrm{~K}$ and $1 \mathrm{~K}$. Biases observed in the Northern Hemisphere are in general comparable to biases observed in the Southern Hemisphere. Spectral residuals obtained in the tropics have 

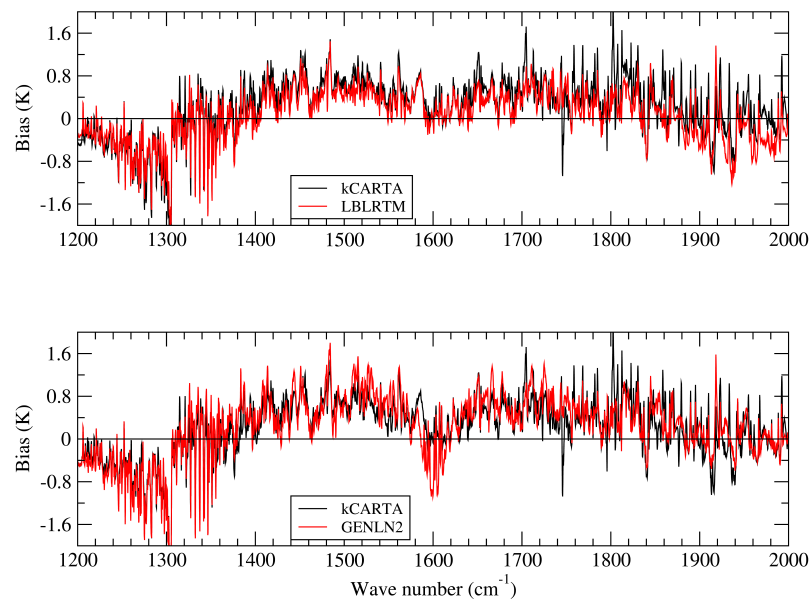

Fig. 9. The mean value of the difference between observed and computed brightness temperatures in the tropical region for IASI band 2 .
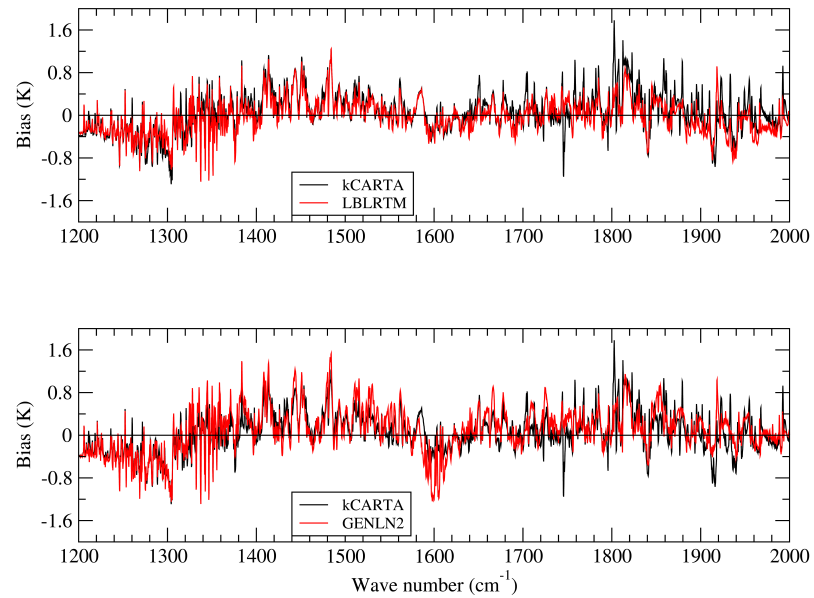

Fig. 10. The mean value of the difference between observed and computed brightness temperatures in the Southern Hemisphere for IASI band 2 .

more spectral structure and the biases observed in this region are larger than the biases observed in the other geographical regions. In addition, the differences between the spectral residuals obtained in the tropics are larger than the differences between the spectral residuals obtained elsewhere. A feature of the tropical spectral residuals is an offset towards positive values that is largely absent in the other geographical regions. This behaviour could point to a possible systematic moist bias in the ECMWF tropical humidity fields. Given the high water vapour loadings encountered in tropical conditions, errors in the water vapour line strenghts can have a significant impact on simulated radiances. To this end, it has been recently reported (Coudert et al., 2008) that in the $1000-2000 \mathrm{~cm}^{-1}$ region, the HITRAN 2004 database underestimates by between $5 \%$ and $10 \%$ the line intensities of the stronger transitions.
In all geographical regions, the larger biases correspond to channels located in the spectral region characterized by the presence of the strong $v 4$-band of methane at $1310 \mathrm{~cm}^{-1}$ where negative values are in general observed. The larger biases in this region can be partly explained by the fact that methane amounts are fixed to climatological values.

LBLRTM and kCARTA spectral residuals exhibit very similar features in the left side and central part of the water vapour $v 2$-band from 1400 up to $1700 \mathrm{~cm}^{-1}$. In this spectral region the GENLN2 spectrum is more irregular and probably reflects differences in the spectroscopy. This is all the more evident around $1600 \mathrm{~cm}^{-1}$ where GENLN2 shows significantly larger biases. We interpret this result in terms of the GENLN2 water vapour continuum model. In fact, in the spectral region around $1600 \mathrm{~cm}^{-1}$ the GENLN2 continuum model uses significantly smaller values of the spectral density function (see Fig. 2). To the right side of the band, the structure of the spectral residuals is more irregular. The GENLN spectral residuals follow more closely the LBLRTM spectral residuals and in the case of kCARTA we can observe a consistent number of spikes that are not present in the spectral residuals obtained using the other LBL models. This is very apparent around 1740 and $1800 \mathrm{~cm}^{-1}$. In general, it would appear that LBLRTM tends to fit better the observations although it is difficult to give a conclusive answer since the results can be affected by uncertainties in the water vapour profiles above all in presence of the high water vapour loadings characteristic of tropical conditions. However, we should also note that in the in the tropics and in the Southern Hemisphere the LBLRTM spectral residuals between 1980 and $2000 \mathrm{~cm}^{-1}$ exhibit larger biases than the GENLN2 and kCARTA spectral residuals.

Since GENLN2 and kCARTA use the same molecular database it is difficult to explain the origin of the large spikes in the kCARTA spectral residuals since these cannot attributed to the continuum model as shown in the upper panel of Fig. 11. In this panel, we have plotted the difference between the kCARTA_MT_CKD_1.0_UMBC mean spectrum and the kCARTA_MT_CKD_1.0 mean spectrum computed in the tropical region. Results in the upper panel of Fig. 11 show that in IASI band 2, differences between the kCARTA and LBLRTM continuum can only have a significant impact in the regions at the edges of the band. Hence, the vast majority of the spikes seen in kCARTA cannot be attributed to the continuum model. The same conclusion also applies to the spectra obtained in the other geographical regions although the results are not shown here. It could be argued that the kCARTA spikes could be a feature of the fast transmittance model used in RTTOV. However, in IASI band 1 and IASI band 2 the predictors used to compute the KCARTA coefficients are the same as those used for the LBLRTM and GENLN2 coefficients. Although the computation of the water vapour coefficients involve the weighting of the input data prior to the regression, to our knowledge the details of the procedure used to perform this operation for the kCARTA 

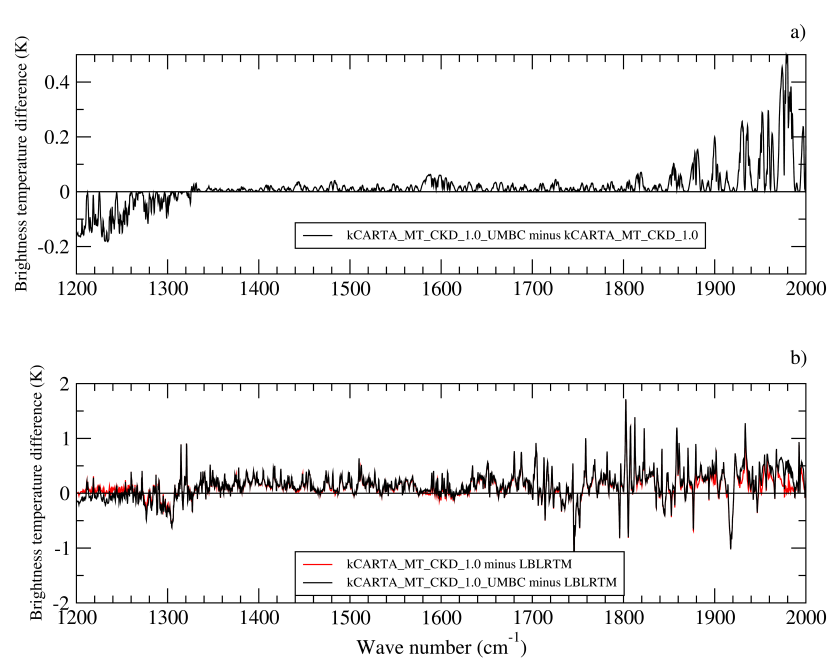

Fig. 11. The difference in IASI band 2 between (a) kCARTA_MT_CKD_1.0_UMBC and kCARTA_MT_CKD_1.0 mean spectrum in the tropical region; b) kCARTA_MT_CKD_1.0_UMBC and LBLRTM (solid black line) and kCARTA_MT_CKD_1.0 and LBLRTM (solid red line) mean spectrum in the tropical region.

coefficients does not differ from the procedure adopted for the GENLN2 and LBLRTM coefficients.

Finally, in the lower panel of Fig. 11 we have superimposed the tropical spectra that show the difference between the kCARTA_MT_CKD_1.0_UMBC mean spectrum and the LBLRTM mean spectrum and the difference between the kCARTA_MT_CKD_1.0 mean spectrum and the LBLRTM mean spectrum. Results in the lower panel of Fig. 11 show that differences between KCARTA and LBLRTM in the region between 1970 and $1990 \mathrm{~cm}^{-1}$ and between 1200 and $1280 \mathrm{~cm}^{-1}$ are almost entirely attributable to the continuum model. The same can be said for the spectra in the Southern Hemisphere although the results are not shown here.

\subsection{IASI band $3\left(2000\right.$ to $\left.2760 \mathrm{~cm}^{-1}\right)$}

Results for IASI band 3 are shown in Figs. 12, 13 and 14 for the Northern Hemisphere, tropics and Southern Hemisphere respectively. The larger biases between 2080 and $2200 \mathrm{~cm}^{-1}$ in the Southern Hemisphere and in the tropics reflect latitudinal gradients of $\mathrm{CO}$ amounts not accounted for in the RT computations. In the same spectral region biases in the Northern Hemisphere vary between $-0.4 \mathrm{~K}$ and $0.4 \mathrm{~K}$ reflecting smaller CO latitudinal gradients in this geographical region. Very noticeable are the large spikes in the kCARTA spectra between 2000 and $2150 \mathrm{~cm}^{-1}$.

\subsubsection{Results in the temperature sounding band}

The $\mathrm{N}_{2} \mathrm{O} / \mathrm{CO}_{2} v 3$-region between 2200 and $2300 \mathrm{~cm}^{-1}$ is characterized by the presence of tropospheric temperature sounding channels analogous to those present in the $\mathrm{CO}_{2} v 2$ -
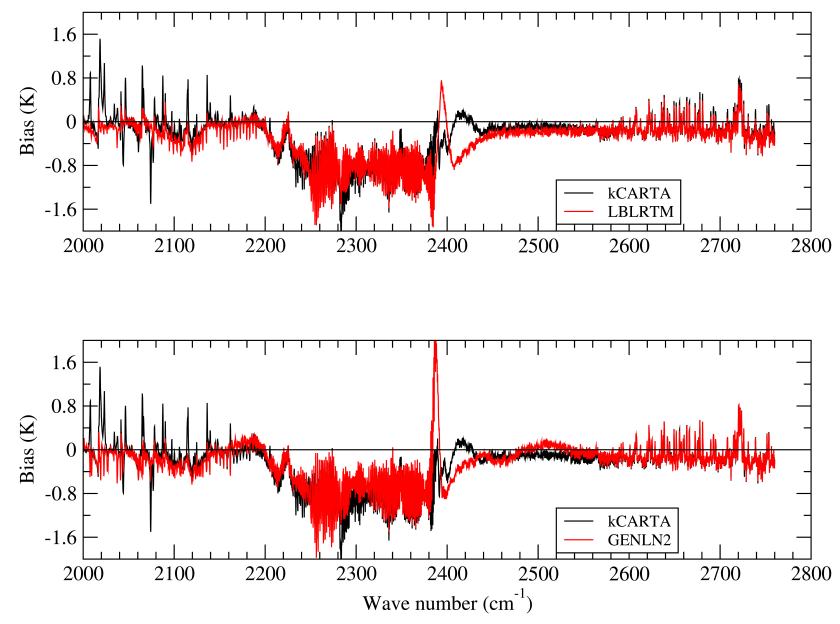

Fig. 12. The mean value of the difference between observed and computed brightness temperatures in the Northern Hemisphere for IASI band 3 .
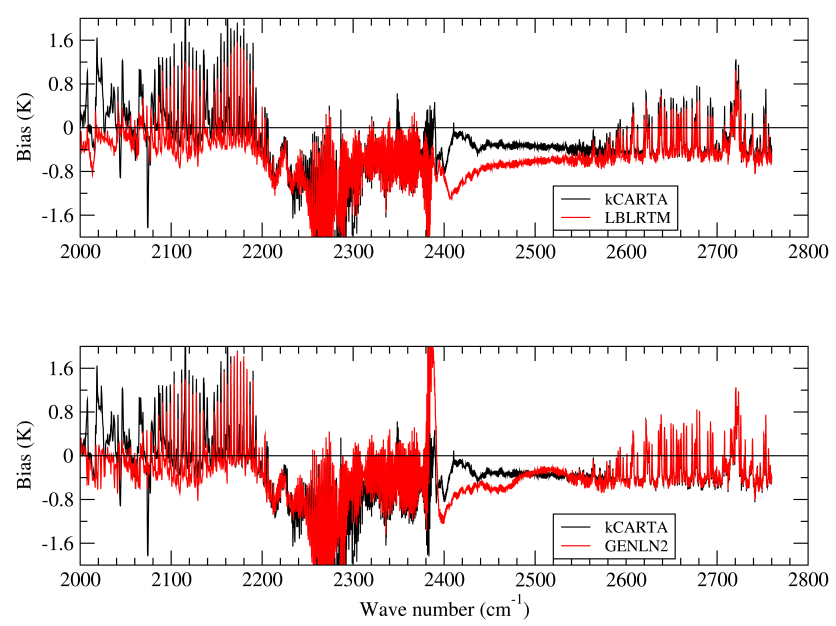

Fig. 13. The mean value of the difference between observed and computed brightness temperatures in the tropical region for IASI band 3 .

region between 700 and $750 \mathrm{~cm}^{-1}$. For these channels, the large residuals obtained in the $v 3$-region are inconsistent with the smaller residuals observed in the $v 2$-region suggesting that residuals between 2200 and $2300 \mathrm{~cm}^{-1}$ are dominated by spectroscopic errors. The region between 2300 and $2380 \mathrm{~cm}^{-1}$ sees the presence of a large number of channels characterized by very high-peaking weighting functions with tails that can extend well into $0.2 \mathrm{hPa}$. Consequently, the large biases observed in this region could be associated to systematic biases in the ECMWF stratospheric and mesospheric temperature profiles. It should also be noted that because of the symmetry of the states involved in the molecular transitions, $\mathrm{P} / \mathrm{R}$-branch line mixing is expected to be twice as strong than in the $v 2$-region. 

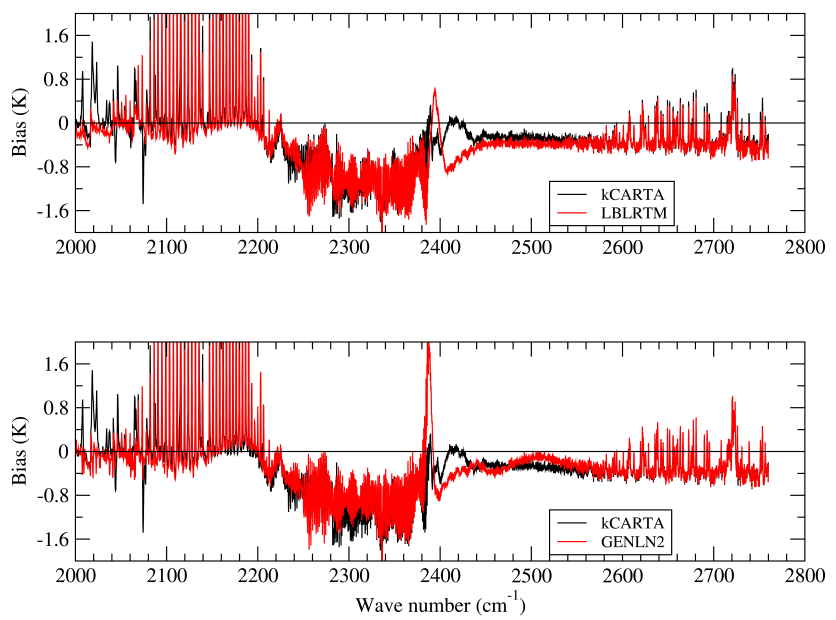

Fig. 14. The mean value of the difference between observed and computed brightness temperatures in the Southern Hemisphere for IASI band 3 .

Between 2200 and $2380 \mathrm{~cm}^{-1}$ biases in the Northern and Southern Hemisphere assume negative values that vary between $-1.8 \mathrm{~K}$ and $-0.4 \mathrm{~K}$. LBLRTM and GENLN exhibit larger biases around $2260 \mathrm{~cm}^{-1}$ whereas kCARTA exhibits larger biases around $2280 \mathrm{~cm}^{-1}$. Biases between 2320 and $2380 \mathrm{~cm}^{-1}$ are very similar. In the tropical region we observe the same pattern. However, biases between 2320 and $2380 \mathrm{~cm}^{-1}$ are now smaller whereas biases around $2280 \mathrm{~cm}^{-1}$ are much larger with GENLN2 attaining values as large as $-3 \mathrm{~K}$. We tend to interpret the close similarities between the GENLN2 and LBLRTM spectra in terms of the line mixing model.

As shown in our plots, GENLN2 spectral residuals in the region between 2380 and $2400 \mathrm{~cm}^{-1}$ (i.e. the far wing of the $\mathrm{CO}_{2} \mathrm{R}$-branch of the $\nu 3$-band) are typically larger than the spectral residuals obtained in the equivalent kCARTA and LBLRTM cases. Given the importance of P/R-branch line mixing in this region, we tend interpret this result as a consequence of errors in the GENLN2 Cousin $\mathrm{CO}_{2}$ line shape. If the behaviour of GENLN2 is justified on the grounds of inaccurate line shape, the LBLRTM residuals show that there are still issues with the modelling of $\mathrm{CO}_{2}$ line shape in the $\mathrm{CO}_{2} v 3$-bandhead. This is also true, albeit to a much lesser extent, for kCARTA. In particular, between 2380 and $2400 \mathrm{~cm}^{-1}$ the LBLRTM spectra show large oscillations whose amplitude can reach almost $3 \mathrm{~K}$ in the Northern Hemisphere. It is possible that this result could be associated to biases in the ECMWF temperature profiles but we would like to bring forward the hypothesis that this behaviour might in fact be related to the treatment of the $\mathrm{CO}_{2}$ continuum in LBLRTM. Our spectra could indicate that the scaling factor of 0.75 applied to the $\mathrm{CO}_{2}$ continuum might not be universally valid.
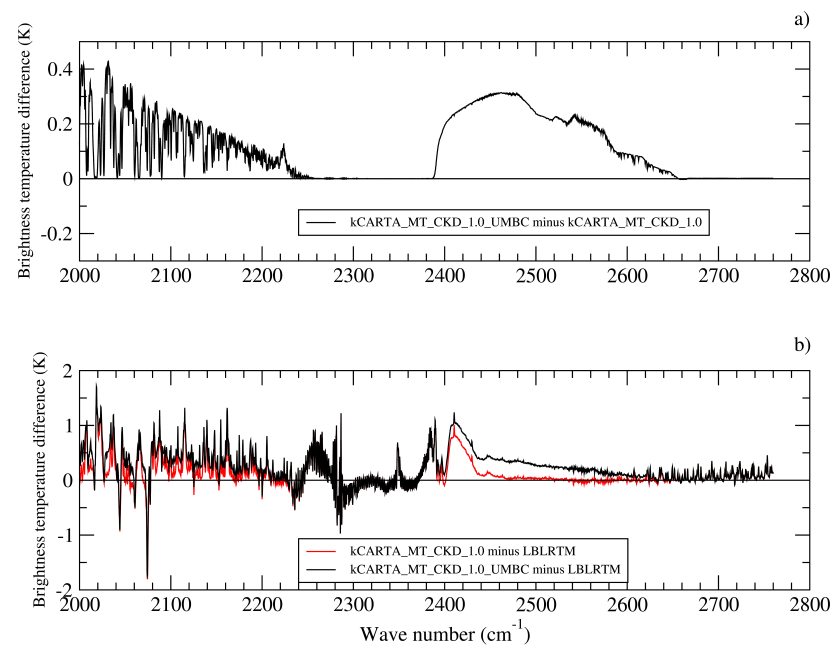

Fig. 15. KCARTA (a) (b) line) and kCARTA_MT_CKD_1.0 and LBLRTM (solid red line) mean spectrum in the tropical region.

\subsubsection{Results in the window region}

Biases in the $2500 \mathrm{~cm}^{-1}$ window region tend to be influenced by the same factors discussed in Sect. 5.1.3. It should be noted that the water vapour continuum in band 3 is known to a lesser accuracy than in band 1 . As in band 1, spectral residuals in the Horthern and Southern Hemispheres are closer than spectral residuals in the tropics. However, opposite to what observed in band 1, biases in the Southern Hemisphere tend to be larger than biases in the Northern Hemisphere. Biases are generally negative but a small number of positive values are also observed. In terms of absolute values, biases vary between -0.4 and $0.8 \mathrm{~K}$.

Differences between the spectral residuals largely reflect differences between the continua models. The top panel in Fig. 15 shows the difference between kCARTA_MT_CKD_1.0_UMBC and kCARTA_MT_CKD_1.0 in the tropical region and illustrates how the change of the continuum model has an impact between 2380 and $2660 \mathrm{~cm}^{-1}$. The bottom panel shows that the use of the same continuum model has reduced to naught differences between KCARTA and LBLRTM in the 2440 to $2624 \mathrm{~cm}^{-1}$ spectral region. Hence, in this spectral region differences between KCARTA and LBLRTM can be attributed solely to the continuum; it would also appear that the kCARTA residuals are in better agreement with the observations suggesting that the modifications made to the continuum model have improved the accuracy of RT computations. It should also be noted that, as shown in Fig. 15, between 2400 and $2440 \mathrm{~cm}^{-1}$ most of the differences between the LBLRTM and kCARTA spectra 
cannot be attributed to the water vapour continuum. In this spectral interval, the broad features of the LBLRTM residuals are more similar to the features of the GENLN2 residual than to the features of the kCARTA residuals. A possible explanation of this behaviour could lie in the implementation of the $\mathrm{CO}_{2}$ continuum. The implementation of the Nitrogen continuum absorption might also play a role although it is an unlikely factor given the fact that kCARTA and LBLRTM use the same model.

Beyond $2624 \mathrm{~cm}^{-1}$, differences between the spectra are attributable to the water vapour spectroscopy. This is clearly demonstrated by the fact the kCARTA spectral residuals are in better agreement with the GENLN2 spectral residuals (the two models use the same molecular database). In this region dominated by line absorption, results tend to suggest that the spectroscopic parameters used in LBLRTM fit marginally better the observations.

\section{Conclusions}

Three baseline ECMWF monitoring experiments have been carried out to compare IASI observed radiances to radiances simulated by the RTTOV fast radiative transfer model using regression coefficients based on the GENLN2, kCARTA and LBLRTM LBL models using different molecular databases. Results obtained utilizing IASI spectra between the 1st April 2008 and the 15th April 2008 using clear channels (i.e. channels not affected by clouds) over the sea show that in the Northern and Southern Hemisphere biases in IASI band 1 and 2 are typically within $\pm 1 \mathrm{~K}$. Biases in the water vapour $v 2$-band do increase in the tropics where spectral residuals show an offset towards positive values not seen in the other geographical regions. This feature could point to a systematic moist bias in the ECMWF tropical humidity fields. The use of the MT_CKD_v2.0 continuum model results in a reduction up to $1 \mathrm{~K}$ of the biases in the region around $1600 \mathrm{~cm}^{-1}$. The large biases observed in the ozone band, particularly in the Northern Hemisphere, probably reflect errors in the ozone profiles due to a poor performance of the ozone assimilation system.

A more accurate description of the $\mathrm{CO}_{2}$ line shape has a significant impact on the simulated radiances in the $\mathrm{CO}_{2} \nu 2$ region resulting in a reduction of the biases up to $1 \mathrm{~K}$. In the same region, large biases are observed in the GENLN2 and LBLRTM spectral residuals in the $\mathrm{CO}_{2}$ Q-branch at $667 \mathrm{~cm}^{-1}$. These large biases are probably dominated by $\mathrm{CO}_{2}$ line mixing although we cannot rule out that systematic errors in the ECMWF stratospheric/mesospheric temperature profiles are also playing a role. The envelope of the residuals in the spectral region between $700 \mathrm{~cm}^{-1}$ and $750 \mathrm{~cm}^{-1}$ suggest an incorrect specification of the temperature lapse rate in the troposphere with possible implications for the residuals obtained in other sounding regions. Residuals for the tropospheric sounding channels in the region be- tween $2200 \mathrm{~cm}^{-1}$ and $2300 \mathrm{~cm}^{-1}$ are inconsistent (i.e. too negative) with the residuals observed for the equivalent tropospheric channels in the v2-region. We interpret this result in terms of errors in the $\mathrm{CO}_{2}$ line parameters in this region whereas residuals for the high-peaking channels between $2300 \mathrm{~cm}^{-1}$ and $2380 \mathrm{~cm}^{-1}$ are probably dominated by systematic errors in the ECMWF temperature profiles at high altitudes. The kCARTA and LBLRTM improvements in the $\mathrm{CO}_{2}$ line shape result in smaller biases in the $\mathrm{CO}_{2}$ v3-bandhead. However, the LBLRTM spectral residuals display large oscillations not seen in the kCARTA residuals. We have tentatively suggested that this behaviour might be due to the scaling factor utilized in the LBLRTM $\mathrm{CO}_{2}$ continuum model or, more in general, to the implementation of the $\mathrm{CO}_{2}$ continuum model itself.

Finally, we want to conclude by noting that we are aware of the limitations inherent in the study of RT and spectroscopic errors using an NWP environment. We have stressed, for instance, that systematic profile errors can affect the results. However, an NWP system offers the unique possibility of using a very robust statistical sample made of a large number of data obtained in very diverse conditions. In many instances, results obtained in this study are consistent with results obtained by using aircraft data in very controlled atmospheric situations albeit their interpretation may differ. This encourages us in continuing pursuing this effort above all in the light of the continuous improvements made in NWP.

Acknowledgements. IASI has been developed and built under the responsibility of the Centre National d'Etudes Spatiales (CNES, France). It is flown onboard the Metop satellites as part of the EUMETSAT Polar System. The IASI L1 data are received through the EUMETCast near real time data distribution service. We want to thank P. Brunel (Météo France) for having made available the kCARTA coefficients, C. Clerbaux (Service d'Aéronomie) for having made available concentrations for minor gas species, $\mathrm{T}$. McNally (ECMWF) for the very helpful collaboration received during the set up of the monitoring experiments and A. Collard (ECMWF) and N. Bormann (ECMWF) for the implementation of IASI and RTTOV-9 in the ECMWF data assimilation system. Finally, we want to thank all the reviewers for their effort in helping improving the quality of the paper.

Edited by: T. Wagner

\section{References}

Aumann, H. H., Chahine, M. T., Gautier, C., Goldberg, M. D., Kalnay, E., McMillin, L. M., Revercomb, H., Rosenkranz, P. W., Smith, W. L., Staelin, D. H.,Strow, L. L., and Susskind, J.: AIRS/AMSU/HSB on the Aqua mission: design, science objectives, data products, and processing systems, Geoscience and Remote Sensing, IEEE T., 41(2), 253-264, 2003.

Brunel, P. and Turner, S.: On the use of Planck-weighted transmittances in RTTOV, Proceedings of the 13h International TOVS study conference, Ste Adele, Canada, 2003. 
Chalon, G., Cayla, F., and Diebel, D.: IASI: An Advanced Sounder for Operational Meteorology, Proceedings of the 52th Congress of IAF, Tolouse, France, 2001.

Chevallier, F.: Sampled database of 60-level atmospheric profiles from the ECMWF analyses, NWP SAF Report No. NWPSAFEC-TR-001, 2000.

Clough, S. A., Kneizys, F. X., and Davis, R. W.: Line shape and the water vapour continuum, Atmos. Res., 23, 229-241, 1989.

Clough, S. A., Shepard, M. W., Mlawer, E. J., Delamere, J. S., Iacono, M. J., Cady-Pereira, K. E., Boukabara, S., and Brown, P.D.: Atmospheric radiative transfer modelling: a summary of the AER codes, J. Quant. Spectrosc. Radiat. Transfer, 91, 233244, 2005.

Collard, A. D. and McNally, A.P.: Assimilation of IASI radiances at ECMWF, Q. J. Roy. Meteorol. Soc., in review, 2008.

Coudert, L., H., Wagner, G., Birk, M., Baranov, Yu I., Lafferty, W.J., and Flaud, J.-M.: The $\mathrm{H}_{2}^{16} \mathrm{O}$ molecule: Line poisition and line intensity analyses up to the seconf triad, J. Mol. Spectrosc., doi:10.1016/j.jms.2008.03.021, 2008.

Cousin, C., Le Doucen, R., Boulet, C., and Henry, H.: Temperature dependence of the absorption in the region beyond the $4.3 \mu \mathrm{m}$ band head of $\mathrm{CO}_{2}$. Part 2: $\mathrm{N}_{2}$ and $\mathrm{O}_{2}$ broadening, Appl. Opt., 24, 3899-3907, 1985.

De Souza-Machado, Strow, L. L., Tobin, D., Motteler, H., and Hannon, S. E.: Improved atmospheric radiance calculations using $\mathrm{CO}_{2} \mathrm{p} / \mathrm{r}$-branch line mixing, in Proc. Euro. Symp. Aerospace Remote Sensing Europto Series, 1996.

De Souza-Machado, Strow, L. L., Motteler, H., and Hannon, S. E.: kCARTA: an atmospheric radiative transfer algorithm using compressed lookup tables. Univ. Maryland Baltimore County, Dept. Physics, Tech. Report, online available at: http://asl.umbc. edu/pub/rta/kcarta, 2002.

Edwards, D. P.: GENLN2. A general Line-by-Line Atmospheric Transmittance and Radiance Model, NCAR Technical note NCAR/TN-367+STR, National Center for Atmospheric Research, Boulder,Co, 1992.

Eyre, J. R. and Woolf, H. M.: Transmittance of atmospheric gases in the microwave region: a fast model, Appl. Opt. 27, 3244-3249, 1988.

Hauglustaine, D. A., Brasseur, G. P., Walters, S., Rasch, P. J., Müller, J.-F., Emmons, L. K., and Carroll, M. A.: MOZART, a global chemical transport model for ozone and related chemical tracers, 2, Model results and evaluation, J. Geophys. Res., 103, 28291-28335, 1998.

Jacquinet-Husson, N., Scott, N. A., Chedin, A., Garceran, K., Armante, R., Chursin, A. A., Barbe, A., Birk, M., Brown, L. R., Camy-Peyret, C., Claveau, C., Clerbaux, C., Coheur, P.F., Dana, V., Daumont, L.,Debacker-Barilly, M. R., Flaud, J. M., Goldman, A., Hamdouni, A., Hess, M., Jacquemart, D., Kopke, P., Mandin, J. Y., Massie, S., Mikhailenko, S., Nemtchinov, V., Nikitin, A., Newnham, D., Perrin, A., Perevalov, V. I., RegaliaJarlot, L., Rublev, A., Schreier, F., Schult, I., Smith, K. M., Tashkun, S. A., Teffo, J. L., Toth, R. A., Tyuterev, V. G., Vander Auwera, Varanasi, J. P., and Wagner, G.: The 2003 edition of the GEISA/IASI spectroscopic database, J. Quant. Spectrosc. Radiat. T., 95, 429-467, 2005.

Kara, A. B. and Barron, C. N.: Fine-resolution satellite-based daily sea surface temperatures over the global ocean, J. Geophys. Res., 112, C05041, doi:10.1029/2006JC004021, 2007.
Lafferty, W. J., Solodov, A. M., Weber, A., Olson, W. B., and Hartman, J.-M.: Infrared collision-induced absorption by N2 near 4.3 $\mu \mathrm{m}$ for atmospheric applications: measurements and empirical modelling, Apl. Opt., 35, 5911-5917, 1996.

Ma, Q., Tipping, R. H., and Leforestier, C.: Temperature dependences of mechanisms responsible for the water-vapor continuum absorption: 1. Far wings of allowed lines. J. Chem. Phys., 128, 124313, doi:10.1063/1.2839604, 2008.

Matricardi, M. and Saunders, R.: Fast Radiative Transfer Model for Simulation of Infrared Atmospheric Sounding Interferometer Radiances, Appl. Opt. 38, 5679-5691, 1999.

Matricardi, M.: RTIASI-4, a new version of the ECMWF fast radiative transfer model for the infrared atmospheric sounding interferometer, ECMWF Research Dept. Tech. Memo. 345, online available at: http://www.ecmwf.int/publications, 2003.

Matricardi, M., Chevallier, F., Kelly, G., and Thepaut, J.-N.: An improved general fast radiative transfer model for the assimilation of radiance observations, Q. J. Roy. Meteorol. Soc., 130, 153173, 2004.

Matricardi, M.: An inter-comparison of line-by-line radiative transfer models, ECMWF Research Dept. Tech. Memo. 525, online available at: http://www.ecmwf.int/publications, 2007.

Matricardi, M.: The generation of RTTOV regression coefficients for IASI and AIRS using a new profile training set and a new lineby-line database, ECMWF Research Dept. Tech. Memo. 564, online available at: http://www.ecmwf.int/publications, 2008.

McNally, A. P. and Watts, P. D.: A cloud detection algorithm for high-spectral-resolution infrared sounders, Q. J. Roy. Meteorol. Soc., 129, 3411-3423, 2003.

McNally, A. P., Watts, P. D., Smith, J. A., Engelen, R., Kelly, G. A., Thepaut, J. N., and Matricardi, M.: The assimilation of AIRS radiance data at ECMWF, Q. J. Roy. Meteorol. Soc., 132, 935957, 2006.

Menoux, V., Le Doucen, R., Boulet, C., Roblin, A., and Bouchardy, A. M: Collision induced absorption in the fundamental Band of N2, Appl. Opt., 32. 263-268, 1993.

Niro, F., Jucks, K., and Hartmann, J.-M.: Spectra calculations in central and wing regions of $\mathrm{CO}_{2}$ IR bands. IV: software and database for the computation of atmospheric spectra, J. Quant. Spectr. Rad. T., 95(4), 469-481, 2005.

Rabier, F., Thepaut, J.-N., and Courtier, P.: Extended assimilation and forecast experiments with a four dimensional variational assimilation scheme, Q. J. Roy. Meteorol. Soc., 132, 935-957, 1998.

Rinsland, C. P., Zander, J. S., Namkung, J. S., Farmer, C. B., and Norton, R. H.: Stratospheric infrared continuum absorption observed by the ATMOS instrument, J. Geoohys., Res., 94, 16303$16322,1989$.

Rizzi, R., Matricardi, M., and Miskolczi, F.: Simulation of Uplooking and Downlooking High-Resolution Radiance Spectra With Two Different Radiative Transfer models, Appl. Opt. 41, 940956, 2002.

Rothman, L. S., Barbe, A., Chris Benner, D., Brown, L. R., CamyPeyret, C., Carleer, M. R., Chance, K., Clerbaux, C., Dana, V., Devi, V. M., Fayt, A., Flaud, J.-M., Gamache, R. R., Goldman, A., Jacquemart, D., Jucks, K. W., Lafferty, W. J., Mandin, J.-Y., Massie, S. T., Nemtchinov, V., Newnham, D. A., Perrin, A., Rinsland, C. P., Schroeder, J., Smith, K. M., Smith, M. A. H., Tang, K., Toth, R. A., Vander Auwera, J., Varanasi, P., and Yoshino, K.: 
The HITRAN molecular spectroscopic database: edition of 2000 including updates through 2001, J. Quant. Spectrosc. Radiat. T., 82, 5-44, 2003.

Rothman, L. S., Jacquemart, D., Barbe, A., Chris Benner, D., Birk, M., Brown, L. R., Carleer, M. R., Chackerian Jr., Chance, C. K., Coudert, L. H., Dana, V., Devi, V. M., Flaud, J. M., Gamache, R. R., Goldman, A., Hartmann, J. M., Jucks, K. W., Maki, A. G., Mandin, J. Y., Massie, S. T., Orphal, J., Perrin, A., Rinsland, C.P., Smith, M. A. H., Tennyson, J., Tolchenov, R. N., Toth, R. A., Vander Auwera, J., Varanasi, P., and Wagner, G.: The HITRAN 2004 molecular spectroscopic database, J. Quant. Spectrosc. Radiat. T., 96, 139-204, 2005.

Saunders, R., Matricardi, M., and Brunel, P.: An improved fast radiative transfer model forassimilation of satellite radiance observations, Q. J. Roy. Meteor. Soc., 144, 1547-1558, 1999.

Saunders, R., Matricardi, M., and Geer, A.: Rttov9.1 users guide, NWP SAF report, Met. Office, 57 pp., 2008.

Shepard, M. W., Clough, S. A., Payne, V. H., Smith, W. L., Kireev, S., and Cady-Pereira, K. E.: Performance of the line-by-line radiative transfer model (LBLRTM) for temperature and species retrievals: IASI case studies from JAIVEx. Atmos. Chem. Phys., in review, 2009.

Sherlock, V.: ISEM-6: Infrared Surface Emissivity Model for RTTOV-6, NWP SAF report, online available at: http://www.metoffice.gov.uk/research/interproj/nwpsaf/rtm/ papers/isem6.pdf, 1999.

Smith, W. L., Woolf, H. M., Hayden, C.M., Wark, D. Q., and McMillin, L.M.: The TIROS-N Operational Vertical Sounder, B. Am. Meteor. Soc., 60, 1177-1187, 1979.

Strow, L. L. and Reuter, D.: Effect of line mixing on atmospheric brightness temperatures near $15 \mu \mathrm{m}$, Appl. Opt., 27, 872-878, 1988.
Strow, L. L., Tobin, D. C., and Hannon, S. E.: A compilation of First-Order Line-Mixing coefficients for $\mathrm{CO}_{2}$ Q-branches. J. Quant. Spectrosc. Radiat. T., 52, 281, 1994.

Strow, L. L., Motteler, H. E., Benson, R. G., Hannon, S. E., and De Souza-Machado, S.: Fast computation of monochromatic infrared atmospheric transmittances using compressed lookup tables, J. Quant. Spectrosc. Radiat. T., 59, 481-493, 1998.

Strow, L. L., Hannon, S. E., De Souza-Machado, Motteler, S. H., and Tobin, D.: An Overview of the AIRS Radiative Transfer Model, IEEE T. Geosci. Remote Sens., 41, 303-313, 2003.

Tibault, F., Menoux, V., Le Doucen, R., Rosenman, L., Hartman, J.-M., and Boulet, C.: Infrared collision induced absorption by O2 near 6.4 microns for atmospheric applications: measurements and empirical modeling, Appl. Opt., 36, 563-567, 1997.

Timofeyev, Y. M. and Tonkov, M. V.: Effect of the induced Oxygen absorption band on the transformation of radiation in the $6 \mu \mathrm{m}$ region of the Earths atmosphere, Izvestiya, Atmos. Ocean. Phys., 14, 437-441, 1978.

Tjemkes, S. A., Patterson, T., Rizzi, R., Shephard, M. W., Clough, S. A., Matricardi, M., Haigh, J. D., Höpfner, M., Payan, S., Trotsenko, A., Scott, N. Rayer, P., Taylor, J. P., Clerbaux, C., Strow, L. L., DeSouza-Machado, S., Tobin, D., and Knuteson, R.: The ISSWG line-by-line inter-comparison experiment, J. Quant. Spectrosc. Radiat. T., 77, 433-453, 2003.

Tobin, D. C.: Infrared spectral lineshapes of water vapour and carbon dioxide, $\mathrm{Ph} . \mathrm{D}$. dissertation, Univ. Maryland Baltimore County, Baltimore, MD, USA, 1996. 